\title{
Sobre o não-lugar da genética de populações
}

\section{About the non-place of population genetics}

\author{
Alberto Lopo Montalvão Neto (montalvaoalberto@gmail.com) \\ Doutorando em Educação. Universidade Estadual de Campinas (Unicamp).
}

\begin{abstract}
Kassiana da Silva Miguel (kassianamiguelunioeste@ gmail.com)
Doutoranda em Educação em Ciências e Matemática. Universidade Estadual do Oeste do Paraná (Unioeste).
\end{abstract}

Lourdes Aparecida Della Justina (lourdesjustina@gmail.com)

Doutora em Educação para a Ciência (Unesp). Professora Associada da Universidade Estadual do Oeste do Paraná (Unioeste).

Resumo: A Genética de Populações ${ }^{1}$ se apresenta como um campo híbrido do conhecimento, visto que é perpassado por questões referentes à Genética e à Evolução, áreas consideradas desafiadoras devido as diferentes dificuldades que vêm sendo apontadas pela literatura no âmbito do ensino. De igual modo, a GP se mostra desafiadora, porém, com um adicional: há pouco espaço para os seus conteúdos em instâncias educacionais. Partindo do pressuposto que a GP ocupa, portanto, um nãolugar, no presente trabalho buscamos discutir a esse respeito. Para isso, mobilizamos noções e princípios da Análise de Discurso de linha francesa pecheutiana, principalmente com base nos estudos de Eni Orlandi e em pesquisas voltadas para o ensino de Ciências que se debruçam sobre questões da linguagem. Para tal, mobilizaremos, principalmente, a noção de silêncio. A partir da escolha do livro didático como exemplo de materialidade que pode nos dar indícios desse não-lugar, nossas reflexões delineiam alguns dos possíveis mecanismos que nos levam a crer que há uma falta de pertencimento da GP no ensino de Ciências e de Biologia. Assim, com base nessas problematizações, apontamos para algumas implicações que essas formas do silêncio podem ter na apropriação dos discursos/conteúdos (sócio)científicos² ${ }^{2}$.

Palavras-chave: Genética de Populações; Silêncio; Não-lugar.

Abstract: The Population Genetics presents itself as a hybrid field of knowledge, since it is permeated by issues related to Genetics and Evolution, areas considered challenging due to the different difficulties that have been pointed out by the literature in the context of teaching. Likewise, Population Genetics is challenging, however, with an additional: there is little space for its contents in educational instances. Based on the assumption that PG occupies, therefore, a non-place, in the present work we seek to

\footnotetext{
${ }^{1}$ Será utilizada a expressão GP no decorrer do texto para referir-se à Genética de Populações.

${ }^{2}$ Consideramos como sociocientíficas as questões que estão na interface entre a sociedade e a Ciência (MONTALVÃO NETO, 2016).
}

Recebido em: 18/01/2021

Aceito em: 24/02/2021 
discuss this matter. For that, we mobilized Discourse Analyses notions and principles of the French Pecheutian line, mainly based on the studies of Eni Orlandi and on researches focused on Science teaching that deal with language issues. For this, we will mobilize, mainly, the notion of silence. From the choice of the textbook as an example of materiality that can give us evidence of this non-place, our reflections outline some of the possible mechanisms that lead us to believe that there is a lack of belonging of the Population Genetics on Science and Biology teaching. Thus, based on these problematizations, we point to some implications that these forms of silence can have in the appropriation of (socio)scientific discourses/contents.

Keywords: Population Genetics; Silence; Non-place.

\section{INTRODUÇÃO}

Ao longo dos últimos anos, diversas são as discussões a respeito de conteúdos que são privilegiados nos currículos e nas abordagens didáticas em detrimento de outros, considerados importantes para a formação (sócio) científica dos sujeitos (GIRALDI, 2005, NASCIMENTO; ALVETTI, 2006, MONTALVÃO NETO; MIGUEL; GIRALDI, 2015, entre outros). Considerando os recentes questionamentos a esse respeito, podemos mencionar que algumas áreas do conhecimento ganham notória importância no âmbito das Ciências Biológicas, dado que têm sido amplamente discutidos desafios, potencialidades e perspectivas a esse respeito. Entre elas, podemos mencionar a Evolução e a Genética.

Sobre a primeira, comumente é apontado que a Evolução é um “[...] tema central e unificador dentro da Biologia, uma vez que sua compreensão se faz necessária para o entendimento de uma série de outros conceitos e processos biológicos" (GOEDERT et al., 2003, p. 1). Ademais, há de se levar em consideração que, entre outras questões importantes a respeito das teorias evolucionistas, diferentes áreas da Biologia alicerçam os seus estudos (paleontologia, embriologia, biogeografia, biologia molecular, entre outros), e que, além disso, essa área integradora "[...] permite o entendimento das relações de parentesco entre os seres vivos" (LIPORINI et al., 2020, p. 263). Assim, Liporini e colaboradores (2020) situam que as ideias evolucionistas, que tiveram origem em propostas de Darwin e Wallace para explicar o meio natural, se colocam como fundamentais nas compreensões sobre a vida. Por isso, consideramos que a busca pelo seu entendimento é algo necessário. 
Todavia, apesar de sua importância, é importante ressaltar que há muitas dificuldades em relação à compreensão das questões evolutivas, principalmente no âmbito do ensino. Entre outras questões, isso se deve ao fato de que a Evolução, muitas vezes, é considerada uma "melhoria" ou, até mesmo, um "aumento de complexidade" (BIZZO, 1991). No entanto, trata-se de uma descendência com modificação, mediante as pressões ambientais exercidas sobre uma espécie, o que nos leva à prerrogativa de que há distorções a respeito de seus conceitos que merecem reflexões substanciais.

A respeito da segunda, a Genética, entre outras questões, compreendemos que, assim como a Evolução, ela é complexa, devido aos níveis de abstração e devido às dificuldades de contextualização de seus conceitos e de suas terminologias (MONTALVÃO NETO; MIGUEL; GIRALDI, 2015). Ademais, por vezes, a Genética é ensinada por meio de abordagens fragmentadas, descontextualizadas e desatualizadas, apresentando-se em materiais didáticos de igual modo (SARDINHA; FONSECA; GOLDBACH, 2009). Nesse sentido, considera-se como desafiador o ensino de Genética, tanto no que concerne ao rápido progresso de conhecimentos do campo, com seu consequente aumento de conteúdo, quanto no que se relaciona à própria formação docente, pelo fato de que, muitas vezes, os professores sentem insegurança para abordar o tema mediante aspectos relativos à sua formação inicial a respeito do mesmo (LOPES; GÜLLICH, 2020). Outrossim, autores como Travessas, Garnero e Marinho (2020) mencionam que questões evolutivas e genéticas têm sido apontadas pela literatura como desafiadoras nos processos de ensino-aprendizagem, apesar da grande importância desses conceitos para a compreensão do cotidiano que envolvem questões como saúde e percepções sobre a hereditariedade, por exemplo.

Consideramos que Genética e Evolução são inter-relacionadas, inclusive historicamente, visto que, desde a consolidação da Biologia, enquanto área de conhecimento, que remonta à metade do século passado, ambas se influenciam, abrindo margens para a reconsideração de questões evolutivas, a partir de questões gênicas, e para a compreensão de questões genéticas por meio de teorias evolucionistas (LIPORINI et al., 2020). Nesse sentido, consideramos que a compreensão do imbricamento dessas duas áreas se torna algo igualmente relevante.

Destarte, a Genética de Populações (GP) aparece como um não-lugar, não apenas na história da produção do conhecimento científico, como também no ensino. Fundamentalmente, a GP é definida como: 
[...] o ramo da Genética que visa à investigação da dinâmica dos genes nas populações naturais, buscando a elucidação dos mecanismos que alteram a sua composição gênica (efeito de fatores evolutivos, isto é, mutações, seleção natural, deriva genética e fluxo gênico de populações migrantes) ou apenas a frequiência genotípica pelo aumento da homozigose (efeito dos casamentos consangüíneos ou da subdivisão da população em grandes isolados) (BEIGUELMAN, 2008, p. 9).

Em síntese, a GP “[...] possui tênue relação com os mecanismos evolutivos das diferentes espécies, explica a evolução, considerando as distribuições das frequências gênicas e características hereditárias" (FLÔRES; COUTINHO, 2017, p. 274). Compreendendo-a como uma área híbrida, que congrega Genética e Evolução, partimos da premissa de que esse não-lugar se relaciona às dificuldades de compreensão de ambas as áreas mencionadas. Destarte, por não-lugar compreendemos “[...] aquele que sabemos que existe mas não percebemos que a ele pertencemos" (MORAES, 2019, p. 1). Outrossim, tem-se o não-lugar como aquele que "[...] não cria nem identidade singular nem relação, mas sim solidão e similitude" (AUGÉ, 2008, p. 95). Mediante essas definições, podemos dizer, então, com base nas discussões idealizadas por Moraes, Montalvão Neto e Morais (2020), que há uma possível escassez de materialidade histórica da GP em relação ao seu ensino. Em outras palavras, isso significa dizer que partimos da premissa de que a GP pode estar sendo silenciada em diferentes instâncias, incluindo a educação científica.

Cabe destacar que essa hipótese tem como base a questão de que poucas pesquisas têm se debruçado a respeito da temática e que, no âmbito educacional, Flôres e Coutinho (2017) apontam que os desafios no ensino de GP se apresentam tanto em relação aos professores, que, por vezes, possuem pouca afinidade com as suas terminologias e conceitos, dadas as lacunas de sua formação inicial sobre o tema, quanto no que diz respeito aos alunos, sendo possível que essa dificuldade de compreensão da GP esteja relacionada a uma "[...] confusão conceitual existente entre esta e a genética mendeliana" (FLÔRES; COUTINHO, 2017, p. 274). Ademais, Flôres e Coutinho (2017, p. 274) apontam em sua pesquisa que há uma "[...] ausência ou redução no número e no desenvolvimento de estratégias de ensino relativas à GP, percebida principalmente pela baixa produção científica”, o que reafirma as nossas premissas.

Partindo desse cenário, entendemos que a GP se situa num lugar de (des) pertencimento, devido ao seu caráter híbrido e a escassez de materialidade histórica no 
Edição Especial: I SSAPEC - Simpósio Sul-Americano de Pesquisa em Ensino de Ciências

ISSN: 2595- $4520 \quad$ Vol. 4 n. 3. 2021

âmbito do ensino. Assim, este trabalho objetiva discutir algumas questões sobre o nãolugar da GP. Para isso, aliados às perspectivas enunciadas, nos filiamos aos pressupostos da Análise de Discurso de linha francesa ${ }^{3}$, que teve em Michel Pêcheux um de seus principais idealizadores e, principalmente, em estudos de Eni Orlandi, bem como de outros pesquisadores que pensam sobre a linguagem na interface com o ensino de Ciências/Biologia.

\section{ASPECTOS TEÓRICOS E METODOLÓGICOS DA PESQUISA}

Para a realização do diálogo proposto neste estudo, estabelecemos como corpus de análise um livro didático de Biologia do Ensino Médio. A escolha por essa materialidade se justifica pelo fato de que o livro didático se caracteriza como um importante recurso didático utilizado no âmbito escolar. Isso porque se trata de um dos principais materiais disponíveis para auxiliar as práticas de ensino-aprendizagem, sendo utilizado com diferentes finalidades e a partir de distintas formas de uso, e que, portanto, influencia as diferentes práticas de professores e alunos realizadas em sala de aula (MEGID NETO; FRACALANZA, 2003, MONTALVÃO NETO, 2016, SILVA; MEGLHIORATTI, 2020, entre outros).

Sobre esse aspecto, Megid Neto e Fracalanza (2003) já apontavam, no início deste século, para os diferentes usos dos livros didáticos pelos professores. Ao realizarem uma pesquisa para compreender as concepções de professores de escolas públicas do interior paulista, os autores observaram que os docentes utilizam tal recurso como apoio à realização de atividades de ensino-aprendizagem, como fonte de pesquisa bibliográfica ou na elaboração do planejamento e preparação de aulas, algo que ainda parece bastante comum atualmente, principalmente quando olhamos para recentes pesquisas que se debruçam sobre o tema. Silva e Meglhioratti (2020, p. 260), por exemplo, apontam que o livro didático comumente é "[...] utilizado pelo professor para organizar, desenvolver e avaliar o seu trabalho pedagógico".

Diante de uma abordagem de pesquisa que tem como foco o livro didático, consideramos que explicitar a noção de texto é algo fundamental, visto que reconhecemos que o livro didático é composto por diferentes materialidades linguísticas escritas, imagéticas (figuras, fotos, ilustrações etc.), representacionais (esquemas,

${ }^{3} \mathrm{AD}$ daqui em diante.

Recebido em: 18/01/2021

Aceito em: 24/02/2021 
modelos, gráficos etc.), entre outras. Nesse sentido, reconhecendo que o texto é a unidade fundamental de sentido, partimos do pressuposto de que para compreendê-lo:

[...] o leitor deve se relacionar com os diferentes processos de significação que acontecem em um texto. Esses processos, por sua vez, são função da sua historicidade. Compreender como um texto funciona, como ele produz sentidos, é compreendê-lo enquanto objeto linguístico-histórico, é explicitar como ele realiza a discursividade que o constitui. Os textos individualizam como unidade - um conjunto de relações significativas (ORLANDI, 2003, p. $70)$.

Tão importante quanto apontar para o fato de que os textos se relacionam a diferentes processos de significação é compreender as heterogeneidades que os atravessam. Nessa relação, compreende-se que todo texto é heterogêneo:

[...] quanto à natureza dos diferentes materiais simbólicos (imagem, som, grafia etc); quanto à natureza das linguagens (oral, escrita, científica, literária, narrativa, descrição etc); quanto às posições do sujeito. Além disso podemos considerar essas diferenças em função das formações discursivas: em um texto não encontramos apenas uma formação discursiva, pois ele pode ser atravessado por várias formações que nele se organizam em função de uma dominante (ORLANDI, 2003, p. 70).

Nesse contexto de explanações, por formação discursiva compreendemos “[...] aquilo que numa formação ideológica dada - ou seja, a partir de uma posição dada em uma conjuntura sócio-histórica dada - determina o que pode e deve ser dito" (ORLANDI, 2003, p. 43). Nesse sentido, a análise do texto é realizada mediante a observação e a compreensão da inscrição numa dada formação discursiva para a produção de sentidos que são determinados ideologicamente na sua relação com a história.

Nesse sentido, filiados aos pressupostos teóricos da $\mathrm{AD}$, no presente estudo discutimos sobre as questões supramencionadas, mobilizando, principalmente, a noção de silêncio. É necessário, portanto, mencionar que entendemos discurso como sendo o efeito de sentido entre interlocutores (ORLANDI, 2003). Nesse sentido, levamos em consideração a relação sujeito-história-mundo, de tal como que, ao mobilizarmos algumas noções e princípios desse referencial teórico-metodológico, consideramos sujeitos e sentidos em sua relação histórica, com a ideologia. Ainda, vale destacar que, nessa relação, forma e conteúdo são indissociáveis (PÊCHEUX, 1990, ORLANDI, 2003), de tal como que o que se fala e como se fala, ou mesmo aquilo que não é dito, significa.

Especificamente sobre a noção de silêncio, Orlandi (1996) aponta que há duas formas do silêncio: a) o constitutivo, em que o sujeito tem a "Ilusão de que o sentido 
nasce ali, não tem história. Esse é um silenciamento necessário, inconsciente, constitutivo para que o sujeito estabeleça sua posição, o lugar de seu dizer possível" (ORLANDI, 1996, p. 72); e b) a censura, quando não se trata um silêncio necessário, próprio ao processo de significação da linguagem, sendo este, portanto, imposto.

Sobre o funcionamento do silêncio, Orlandi (2007) aponta que tal conceito

[...] atesta o movimento do discurso que se faz na contradição entre o "um" e o "múltiplo", o mesmo e o diferente, entre paráfrase e polissemia. Esse movimento, por sua vez, mostra o movimento contraditório, tanto do sujeito quanto do sentido, fazendo-se no entremeio entre a ilusão de um sentido só (efeito da relação com o interdiscurso) e o equívoco de todos os sentidos (ORLANDI, 2007, p. 17).

A partir do exposto, podemos compreender que há uma relação entre paráfrase e polissemia, entre o já-dito e a emergência de outros dizeres possíveis, que nos ajudam a compreender os efeitos do silêncio. Isso porque, ao se dizer uma determinada coisa, consequentemente, deixa-se de dizer outra, pois, apesar de desejada, a completude do dizer não é possível. Assim, Orlandi (2003) pontua que é próprio da linguagem haver a produção dos efeitos do esquecimento e acrescenta que esse pode ser resultado da forma como a ideologia nos afeta, nos dando a ilusão de que somos a origem do dizer pela ação do interdiscurso (memória discursiva), ou seja, por meio de nossa inscrição na história. Assim, ao esquecer que algo já foi dito, é que o sujeito significa.

Todavia, consideramos que, ao serem silenciados, determinados aspectos, que podem ser socialmente relevantes para a produção de sentidos que se tornam interessantes na compreensão de questões científicas e tecnológicas, podem produzir uma estabilização de sentidos que impeçam a assunção de posicionamentos críticos pelos sujeitos a respeito dessas questões. Nessa relação, tomamos como premissa aquilo que, ao serem privilegiados determinados dizeres (e conteúdos), também ocorre a assunção de um posicionamento ideológico e, mediante disso, entendemos que:

[...] por trás da discussão sobre a seleção dos conteúdos temos um debate mais amplo que nos remete à relevância social, cultural e política do ensino de ciências que nos faz avaliar o porquê de termos presentes determinados conhecimentos em sala de aula (NASCIMENTO; ALVETTI, 2006, p.29).

Nessa relação, entendemos que há silenciamentos, visto que, faz algum tempo, há uma estabilização de conteúdos selecionados para compor os livros didáticos e, assim, ao serem selecionados os mesmos ao longo do tempo, tantos outros são preteridos. Desse modo, concordamos com Giraldi (2005, p. 51), que diz que: 
Ao abordar determinados conteúdos e não outros de forma naturalizada [...], o autor do livro didático está silenciando tanto outros conhecimentos, que podem ser relevantes em contextos de ensino, quanto o processo pelo qual seleciona certas coisas que, segundo ele, devem necessariamente ser trabalhadas na escola" (GIRALDI, 2005, p. 1)

Nessa relação, é preciso considerar, ainda, que tantos outros fatores compõem as condições de produção que atravessam a composição do livro didático. As escolhas dos conteúdos também se relacionam a questões mercadológicas, a questões editoriais, às políticas públicas e aos documentos curriculares a ele relacionados. No entanto, o que queremos apontar é que essa seleção de conteúdos é marcada por silenciamentos, fato esse que nos leva a buscar compreender motivações e possíveis efeitos, sendo a última questão o interesse deste trabalho.

Partindo dessas concepções, consideramos que um olhar, a partir do livro didático, sobre como a GP ocupa um não-lugar no ensino, pode ser promissor, na medida em que nos indica como (e quanto) os conteúdos de GP são abordados no ensino, dando indícios do silenciamento que atravessa a questão. Para a realização dessa análise selecionamos o volume 3 do livro didático Biologia Hoje, dos autores Sérgio Linhares, Fernando Gewandsznadjer e Helena Pacca (editora Ática), visto que nele identificamos expressivamente conteúdos de Evolução e de Genética. Essa escolha justifica-se pelo fato de que este livro figura entre os que tiveram maior circulação nacional entre aqueles aprovados pelo Programa Nacional do Livro Didático (PNLD) de 2015 e de 2018. Desse modo, fizemos uma leitura prévia do livro, a partir da qual identificamos a forma como os conteúdos de GP estão dispostos para a posterior realização de uma análise descritivo-interpretativa, com base em pressupostos da $\mathrm{AD}$, apresentada em nossas análises.

\section{UM OLHAR PARA O NÃO-LUGAR DA GENÉTICA DE POPULAÇÕES A PARTIR DE UM LIVRO DIDÁTICO}

O livro didático em questão possui 20 capítulos, apresentando a seguinte divisão: 7 capítulos voltados ao ensino de Genética; 5 capítulos sobre o ensino de Evolução; 8 capítulos, divididos em duas unidades, voltados ao ensino de Ecologia e assuntos correlatos ao meio ambiente.

Os cinco capítulos que abordam o tema Evolução, e que nos interessam por identificarmos que é nessa seção que se concentram os conteúdos sobre GP, são 
Edição Especial: I SSAPEC - Simpósio Sul-Americano de Pesquisa em Ensino de Ciências ISSN: 2595- $4520 \quad$ Vol. 4 n. 3. 2021

divididos em: capítulo 8 - "Evolução: as primeiras teorias", abordando subtópicos com os títulos "Fixismo", "Lamarckismo" e "Darwinismo"; capítulo 9 - "A teoria sintética: variabilidade genética e seleção natural, Um pouco de História"; capítulo 10 - "A teoria sintética: genética das populações e formação de novas espécies"; Capítulo 11 "Evolução: métodos de estudo", abordando os subtópicos "Fósseis", "Embriologia e anatomia comparadas" e "Estudos moleculares"; Capítulo 12 - "A evolução humana", abordando o tópico "Evolução da espécie humana". Devido às especificidades dos capítulos 9 e 10, referentes às bases da GP, eles serão detalhados a seguir.

O conteúdo referente à GP está na unidade 3, destinada ao ensino de Evolução e centralizado, mais especificamente, no capítulo 10. Esse capítulo, que aborda as questões de GP, possui 14 páginas e faz menção a capítulos anteriores, principalmente a respeito das leis de Mendel, predominante na discussão das primeiras seções do livro sobre Genética. Como mencionado anteriormente, o capítulo tem o título "A teoria sintética: genética das populações e formação de novas espécies”, centrando-se, assim, na "Teoria Sintética da Evolução" para estabelecer relações entre conteúdos de Genética e de Evolução, visto que a teoria trata de questões como combinações gênicas, mutação e seleção natural.

De acordo com Andreatta e Meglhioratti (2009), mediante um ensino de Biologia que ainda se mostra fragmentado e descontextualizado nas escolas, essa teoria pode se apresentar como um eixo unificador. Nessa relação, as autoras apontam que a Teoria sintética da Evolução ou neodarwinismo emerge a partir dos estudos de Ronald Aylmer Fischer (1890-1962), John B. S. Haldane (1892-1964) e Sewall Wright (18891988), que, ao desenvolverem teorias e modelos sobre a frequência e interações gênicas, pautados em estudos mendelianos sobre hereditariedade, situam a seleção natural como fundamental para a compreensão da dinâmica das populações. Tal abordagem leva Theodosius Dobzhansky (1900-1975) a apresentar os estudos neodarwinistas à comunidade científica, estudos esses que tornam a seleção natural algo preponderante nas explicações evolutivas.

O capítulo 10 possui a seguinte distribuição: no tópico "Evolução: uma mudança na frequência dos alelos da população", os estudos apresentados são divididos nas temáticas: 1) "Lei de Hardy-Weinberg" e 2) "Deriva genética"; no qual o tópico "Formação de novas espécies", por sua vez, divide-se em: a) "Isolamento geográfico"; b) "Isolamento reprodutivo"; c) "Mecanismos pré-zigóticos"; d) "Mecanismos pós- 
zigóticos"; e) "Um exemplo de especiação: os tentilhões de Darwin”; f) "Especiação sem isolamento geográfico". Nota-se, portanto, que este capítulo apresenta os principais mecanismos para a compreensão da dinâmica populacional. Essa abordagem ocorre tanto por meio da enunciação de teorias que são consideradas a base dessa área quanto por meio de exemplos que buscam validar as teorias enunciadas ao abordar casos específicos observáveis, num viés de Ciência hipotético-dedutivo ${ }^{4}$, a partir do qual se busca produzir efeitos de verdade.

Cabe ressaltar que apenas em uma caixa de texto, disposta ao final da última seção do décimo capítulo do livro, denominada "Biologia e sociedade", é que ocorre a apresentação de um elemento que se articula a questões socialmente relevantes: a ideia de que raça é uma construção social e não biológica. Outras questões não são estabelecidas ao longo do texto e esse silenciamento contribui para reforçar diversas problematizações, como, por exemplo, a existência de desigualdades e de conflitos sociais emergentes em meio ao atual momento de pandemia da Covid-19. Isso porque o estudo de GP Humanas é fundamental na medida em que:

[...] dedica-se ao estudo da distribuição de freqüências gênicas e de caracteres hereditários normais e patológicos nas populações humanas, bem como aos fatores que mantêm ou, em oposição, alteram as freqüências gênicas ou genotípicas nessas populações. A busca pela compreensão da dinâmica populacional dos genes e dos genótipos normais e patológicos é a razão da importância da Genética de Populações para os estudiosos da Genética Humana e Médica, da Epidemiologia, da Antropologia Física e para aqueles que se dedicam à Biologia Humana e à Evolução, pois é por intermédio do estudo dos fatores evolutivos que entendemos como se faz a manutenção da carga hereditária deletéria através de gerações (BEIGUELMAN, 2008, p. 8).

Por meio do trecho supracitado podemos compreender que a GP abarca diferentes campos do conhecimento, sendo fundamental para a compreensão dos padrões evolutivos das espécies a partir de questões genéticas (frequências gênicas), incluindo a espécie humana. Todavia, as questões relacionadas a esse campo híbrido não se restringem apenas ao âmbito científico. Outrossim, consideramos que as discussões a respeito de temáticas sociais e das aplicabilidades da GP poderiam ser úteis para a compreensão como, por exemplo, sobre o que é um vírus e acerca de sua

\footnotetext{
${ }^{4}$ De acordo com French (2009), este método ocorre a partir da formulação de hipóteses, criadas de forma pontual e espontânea, que são testadas por meio de uma série de regras, que culminam numa dedução que se dá de maneira lógica. A partir disso, ocorrem predições, que podem ser confirmadas ou não. Nesse sentido, para que uma hipótese seja considerada como científica, ela de ser, necessariamente, verificável.
} 
Edição Especial: I SSAPEC - Simpósio Sul-Americano de Pesquisa em Ensino de Ciências ISSN: 2595- $4520 \quad$ Vol. 4 n. 3. 2021

dinâmica epidemiológica, o que, em um momento pandêmico como o que vivemos, em meio ao novo coronavírus, nos parece algo fundamental.

Vale destacar que os vírus são seres microscópicos e parasitas intracelulares obrigatórios, por necessitarem de um hospedeiro para a sua sobrevivência e replicação. Ademais, considera-se que "As propriedades físico-químicas dos vírus os tornam capazes de infectar [...] a interação vírus-hospedeiro é a chave de muitos aspectos das doenças virais, tanto da transmissão quanto da capacidade [...] de se sobrepor as defesas do hospedeiro" (STEPHENS, 2009, p. 127). Nesse sentido, partimos do pressuposto de que aproximar o tema "vírus", bem como elucidar acerca dos padrões de suas mutações e implicações biológicas relacionadas, das questões sociais, dialogando com a população, poderia abrir margens para o controle e para a prevenção de enfermidades, como no caso do novo coronavírus. Isso aponta para a importância de se abordar, em contextos educacionais, as questões científico-sociais que relacionam as temáticas da GP. Todavia, ao olharmos para recursos escolares, como o livro didático, vemos que há um silenciamento das questões sociais em detrimento de explicações estritamente biológicas, o que pode levar a um distanciamento dos sujeitos a respeito do tema e, consequentemente, ao agravamento de crises como a que vivenciamos em meio à pandemia, que não apenas pode ser considerada uma crise sanitária mundial, de saúde pública, como também mostra as suas faces enquanto crise social, política, econômica, ética, ambiental, entre tantas outras problematizações possíveis.

Dessa forma, observamos que o único capítulo dedicado à GP no livro didático analisado privilegia conteúdos e discursos científicos. Do ponto de vista da $\mathrm{AD}$, podemos afirmar que o texto do livro didático se filia a uma Formação Discursiva Científica, em busca de uma aparente neutralidade e objetividade, principalmente pelo uso de terminologias, conceitos, cálculos e exemplos que são usualmente utilizados para a explicação de teorias evolucionistas e genéticas. Entendemos que "[...] aquilo que se fala e como se fala da/sobre ciência e tecnologia produz efeitos de sentidos nos leitores" (LINSINGEN; CASSIANI, 2010, p. 163). Em outras palavras, forma e conteúdo são indissociáveis (PÊCHEUX, 1990, ORLANDI, 2003). Nesse sentido, consideramos que silenciar algumas questões socialmente relevantes e as aplicações das teorias científicas pode se caracterizar como um dos motivos pelos quais a GP ocupa um não-lugar no ensino, visto que o tema parece distanciar-se daqueles que não podem extrapolar aquilo que é apresentado cientificamente pelo livro didático. 
Ao olharmos para os capítulos do livro didático, foco de interesse deste estudo, entre aqueles que mais dialogam com os conteúdos de GP, como elementos temáticos oriundos do capítulo 10, está o capítulo anterior, o número 9, que, como enunciamos, possui o título de "A teoria sintética: variabilidade genética e seleção natural". Apresentando em 12 páginas os conteúdos referentes a esse conhecimento fundamental da Biologia evolutiva, o capítulo mencionado é dividido nos seguintes tópicos: 1) "Um pouco de História", que apresenta os subtópicos: a) "A descoberta dos genes e das mutações" e b) "A teoria atual"; 2) "Variabilidade genética: mutações e reprodução sexuada", que dispõe dos subtópicos: a) "Mutação e evolução", b) "O acaso das mutações" e c) "Reprodução sexuada"; 3 ) "Seleção natural”, que traz os subtópicos: a) "A resistência de bactérias aos antibióticos", b) "Anemia falciforme: exemplo de seleção natural na espécie humana", c) "Seleção sexual” e d) "As limitações da seleção natural". Vale acrescentar que, como em todas as demais unidades do livro didático, são também propostas algumas atividades ao final do capítulo e há uma caixa de texto ao final dos tópicos com o título "Processos evolutivos", que remete aos aspectos biológicos das "Vantagens da reprodução sexuada".

Ao analisarmos o capítulo 9, observamos que a forma como são apresentados os conteúdos e a predominância do discurso científico reforçam o processo parafrástico de estabilização de sentidos, nesse e em outros capítulos, levando o leitor a um distanciamento dessas questões, que se colocam como intangíveis a outro âmbito que não seja aquele pertencente à ordem discursiva científica. Assim, passagens como as expostas a seguir explicitam a neutralidade e objetividade exposta, que, na maior parte do tempo, se demarca por aspectos de impessoalidade:

$O$ conhecimento mais recente sobre o mecanismo do código genético comprovou que as mutações ocorrem ao acaso (LINHARES; GEWANDSNADJER; PACCA, 2016, p. 128, grifos nossos).

Os cientistas já estudaram vários casos de seleção natural (LINHARES; GEWANDSNADJER; PACCA, 2016, p. 129, grifos nossos).

Para alguns pesquisadores, características como a cauda do pavão e o colorido das penas de muitos pássaros ou das escamas de várias espécies de peixes funcionam como um sinal de que o animal não tem doenças causadas por parasitas (LINHARES; GEWANDSNADJER; PACCA, 2016, p. 131, grifos nossos).

Pensando sobre trechos como os que foram apresentados acima, entre outras questões, poderíamos nos perguntar: Quem são esses cientistas/pesquisadores mencionados, que estudaram questões relacionadas à seleção natural? Como o fizeram? Qual seria esse "conhecimento mais recente", mencionado no texto do segundo 
enunciado? Nesse sentido, para além do reduzido espaço destinado à GP, também constatamos que há pouca contextualização acerca de conteúdos inter-relacionados a ela.

Giraldi (2005), ao elaborar conceptualizações, com base em noções e princípios da $\mathrm{AD}$, para a realização de uma análise de livros didáticos com o objetivo de compreender os possíveis efeitos de sentido produzidos sobre Biologia Celular (Citologia), usa como categoria de análise a relação pessoalidade/impessoalidade. Nessa relação dual entre o pessoal e o impessoal, comum ao livro didático, Giraldi (2005, p. 54) aponta que essa categoria "[...] refere-se ao modo como o autor do texto didático faz uso da linguagem, ora aproximando-se da linguagem comum, ora apresentando ideias de modo formal e fazendo uso de termos que retratam o caráter científico de seu discurso". Como enunciado pela autora e por Montalvão Neto (2016), ambos com base em análises de regularidades discursivas apresentadas em livro(s) didático(s), esse tipo de movimento é comum no início de obras desse tipo. Isso porque na introdução de cada capítulo é comum que haja a instauração de diálogos com o leitor, de forma pessoal, sendo que, no decorrer da leitura, geralmente, essa aproximação torna-se cada vez menos frequente. Como por exemplo, logo nas primeiras páginas dos capítulos 9 e 10, observamos falas como as apresentadas a seguir:

Capítulo 9: [...] em ambientes com muitos predadores, os lebistes [espécie de peixe] machos são menos coloridos do que nos ambientes com poucos predadores. Como explicar esse fato? (LINHARES; GEWANDSNADJER; PACCA, 2016, p. 125, grifos nossos).

Capítulo 10: $O$ que você acha que deve acontecer com a frequência de alelos recessivos e dominantes ao longo do tempo? (LINHARES; GEWANDSNADJER; PACCA, 2016, p. 138, grifos nossos).

Podemos notar, por meio dos excertos assinalados anteriormente, que perguntas são feitas diretamente ao leitor, provavelmente não esperando que ele tenha respostas prontas em sua mente, mas de forma a levá-lo a questionar, refletir sobre essas questões ao longo da leitura. Porém, esse movimento de diálogo se torna pouco comum ao longo dos capítulos, que, como apontamos anteriormente, estão filiados a uma rede de sentidos própria a uma formação discursiva científica. Ademais, conforme apontam alguns trabalhos, como os estudos de Giraldi (2005), Montalvão Neto (2016), Montalvão Neto e Almeida (2020), entre outros, esse tipo de discurso representa a produção de efeitos de naturalização de verdades que colocam em pauta um discurso de autoridade a partir da tipologia discursiva denominada discurso científico. Afinal, é por 
meio desse tipo de discurso que se confere aos dizeres sobre Ciência o caráter de autoridade a partir daquilo que pode (e deve) ser dito sobre um determinado tema validado pela posição-sujeito cientista.

É importante ressaltar que a neutralidade e a objetividade expostas por meio desses mecanismos discursivos expostos também são, a nosso ver, modos pelos quais se manifesta o silêncio mediante outras questões: as (sócio) científicas. Nesse sentido, para além do não-lugar da GP marcado por uma falta de materialidade histórica desses conteúdos (MORAES; MONTALVÃO NETO; MORAIS, 2020) em um recurso didático-pedagógico tão importante quanto o livro didático - ou seja, pelo silenciamento do próprio conteúdo de/sobre GP, dadas as escolhas feitas na seleção de conteúdos que integram este material de uso escolar -, compreendemos que há outros mecanismos da linguagem do livro didático que levam à estabilização de sentidos por meio do apagamento de outras questões que não aquelas relativas à ordem discursiva científica. Ademais, cabe ressaltar a existência de ausências e de estabilizações de conteúdos que são comumente selecionados para compor o livro didático, com a consequente, e igualmente comum, simplificação desses conteúdos. Nesse contexto, em meio ao processo de transposição desses conteúdos para compor um recurso de ensino há uma busca por completude nos textos dos livros didáticos (GIRALDI, 2005).

Sobre essa noção da AD, Orlandi (2003) menciona que "[...] o incompleto na linguagem é o lugar do possível, é condição do movimento dos sentidos e dos sujeitos. É na incompletude que escrevemos a questão do silêncio, e, por esta via, a da interpretação como movimento" (ORLANDI, 1996, p. 71). Em outras palavras, apesar de ser comum a sensação de que podemos falar tudo, na perspectiva da linguagem isso tangencia ao impossível. Nesse sentido, não apenas não é possível dizer tudo como ao se dizer algo obrigatoriamente é necessário que se deixe de dizer outra(s) coisa(s). Todavia, o que é posto em causa aqui não se refere ao silêncio necessário para o funcionamento da linguagem. Trata-se de pensar que determinados silêncios levam à estabilização de sentidos outros que, a nosso ver, se tornam fundamentais para a compreensão dos aspectos (sócio) científicos.

Nessa relação, o livro didático se apresenta como um entre tantos outros exemplos que não apenas conferem uma ausência de pertencimento de conteúdos, como a GP, mas que também abre espaço para um não-lugar dos aspectos sociais, políticos e éticos, relativos à saúde e ao cotidiano, que nos permitiriam compreender as relações 
existentes entre as teorias evolutivas e genéticas e os aspectos sócio-históricos. Assim, a escolha por determinados dizeres (e seus mecanismos) e conteúdos nos levam a defender a existência do silenciamento de uma materialidade histórica sobre a GP que nos parece uma questão importante de ser discutida, materialidade essa que se caracteriza pela discussão pífia desse campo híbrido em pesquisas acadêmicas, em materiais didáticos, em currículos e, de igual modo, nas discussões sociais de/sobre Ciência.

Destarte, consideramos que, se almejamos uma população que possa se posicionar perante questões científicas e tecnológicas, adentrando, de fato, nessa ordem discursiva, para pensar em sua relação com o seu cotidiano e com o mundo, cabe-nos, então, questionar os motivos pelos quais determinados conteúdos são privilegiados em detrimento de outros, o que, no que concerne à GP, para esta pesquisa, não foi de nossa pretensão responder, mas apresentar problematizações a respeito disso.

\section{CONSIDERAÇÕES FINAIS}

Na presente pesquisa refletimos a respeito do não-lugar ocupado pela GP. Para isso, utilizamos o livro didático, enquanto uma entre tantas outras materialidades possíveis, para pensar a respeito dessa questão. A partir de reflexões sobre esse importante recurso didático-pedagógico, compreendemos que a GP, apesar de comumente apresentar-se de forma explícita em um único capítulo ou em poucas páginas do livro didático, mais especificamente na unidade que corresponde aos conteúdos relativos à Evolução biológica, não pertence apenas a essa área do conhecimento, visto que, para explicá-la, se faz necessário pensar sobre outras questões além das evolucionistas como, por exemplo, no que se refere aos conceitos e terminologias da Genética.

No entanto, apesar da importância para a compreensão da dinâmica das populações e da vida no planeta Terra, incluindo a vida humana, a GP ocupa um nãolugar, principalmente no âmbito do ensino de Ciências e Biologia. Esse não-lugar se constitui tanto por uma falta de pertencimento da GP a uma área específica, encontrando-se numa posição de entremeio, quanto no que se refere ao distanciamento com que é apresentada para aqueles que não estão numa formação discursiva científica. Há, portanto, uma série de mecanismos discursivos que corroboram para que ocorra essa falta de pertencimento desses conteúdos e esse silenciamento da GP no ensino é 
marcado por um discurso de neutralidade e objetividade científica, o que nos parece problemático mediante uma série de cenários possíveis.

Um exemplo apontado no trabalho a esse respeito são as consequências ocasionadas por um aglomerado de fatores sócio-políticos relativos à pandemia decorrente do novo coronavírus. Em meio a uma série de silenciamentos de questões (sócio) científicas, o público em geral permanece alheio a respeito do que é um vírus bem como sobre como ele sofre mudanças genéticas por meio de diferentes processos dinâmicos, como, por exemplo, a mutação. Tal abordagem nos leva a crer que esse silêncio ocasionado pela escolha de determinados conteúdos comumente privilegiados nos livros didáticos (e/ou nos currículos) acaba por ocasionar implicações na própria apropriação de temas científicos contemporâneos por diversos setores da sociedade, o que leva ao silenciamento não apenas desses conteúdos como também de posicionamentos dos sujeitos perante questões científicas e contemporâneas.

Este trabalho insere-se em um conjunto de reflexões que temos idealizado a fim de tratar sobre as questões epistemológicas concernentes à GP, tanto relativas à Biologia Teórica quanto relacionadas ao seu ensino. Acreditamos que essas reflexões contribuem com o ensino de Biologia na medida em que temos observado em nossas pesquisas que há poucos estudos que se debruçam sobre o tema, sendo nossa pretensão realizar (e abrir margens para) demais abordagens teóricas, empíricas e analíticas que versem sobre essa questão.

\section{REFERÊNCIAS}

ANDREATTA, S. A.; MEGLHIORATTI, F. A. A integração conceitual do conhecimento biológico por meio da Teoria Sintética da Evolução: possibilidades e desafios no ensino de Biologia. Cascavel: Programa de Desenvolvimento Educacional, 2009.

AUGÉ, M. Não lugares: introdução a uma antropologia da supermodernidade. 7. ed. Campinas: Papirus, 2008.

BEIGUELMAN, B. Genética de populações humanas. Ribeirão Preto: SBG, 2008. $235 \mathrm{p}$. 
Edição Especial: I SSAPEC - Simpósio Sul-Americano de Pesquisa em Ensino de Ciências

ISSN: 2595- $4520 \quad$ Vol. 4 n. 3. 2021

BIZZO, N. M. V. Ensino de Evolução e História do Darwinismo. 1991. Tese (Doutorado em Educação) - Faculdade de Educação, Universidade de São Paulo, São Paulo, 1991.

FLÔRES, A. L. Z. D.; COUTINHO, C. Uma investigação sobre as possibilidades de Ensino de Genética de Populações no Ensino Médio. Vivências, v. 13, n. 25, p. 273279, out. 2017.

FRENCH, S. Ciência - Conceitos-chave em Filosofia. Porto Alegre: Artmed, 2009.

GIRALDI, P. M. Linguagem em textos didáticos de citologia: Investigando o uso de analogias. 137 f. Dissertação (Mestrado em Educação Científica e Tecnológica). Curso de Pós-graduação em Educação Científica e Tecnológica. Universidade Federal de Santa Catarina, 2005.

GOEDERT, L.; DELIZOICOV, N. C.; ROSA, V. L. A formação de professores de Biologia e a prática docente - O ensino de Evolução. In: IV Encontro Nacional de Pesquisa em Educação em Ciências - ENPEC, 4., 2003, Bauru/SP. Anais [...]. Bauru/SP: ABRAPEC, 2003.

LINHARES, S. V.; GEWANDSNADJER, F.; PACCA, H. Biologia Hoje. 3. ed. São Paulo: Editora Ática, 2016.

LINSINGEN, I.; CASSIANI, S. Educação CTS em perspectiva discursiva: contribuições dos Estudos Sociais da Ciência e da Tecnologia. REDES, v. 16, n. 31, p. 163-182, 2010.

LIPORINI, T. Q. et al. Ensino de evolução biológica e o desenvolvimento de uma visão materialista, histórico e dialética acerca da realidade. Debates em Educação, v. 12, n. 26, p. 261-282, 2020.

MEGID NETO, J.; FRACALANZA, H. O livro didático de Ciências: problemas e soluções. Ciência \& Educação, v. 9, n. 2, p. 147-157, 2003.

MONTALVÃO NETO, A. L. Discursos de genética em livro didático: Implicações para o ensino de biologia. 209 f. Dissertação (mestrado). Universidade Federal de Santa Catarina, Programa de Pós-Graduação em Educação Científica e Tecnológica, Florianópolis, 2016. 
Edição Especial: I SSAPEC - Simpósio Sul-Americano de Pesquisa em Ensino de Ciências ISSN: $2595-4520 \quad$ Vol. 4 n. 3. 2021

MONTAlVÃO NETO, A. L.; ALMEIDA, M. J. P. M. de. Possíveis efeitos de sentido na leitura sobre biotecnologia presente num livro didático. Research, Society and Development, v. 9, n. 11, p. 1-30, 2020.

MONTALVÃO NETO, A. L.; MIGUEL, K.; GIRALDI, P. M. Paradigmas, hipóteses e descobertas: O Ensino de Biologia e as Leis de Mendel. In: X Encontro Nacional de Pesquisa em Educação em Ciências - ENPEC, 10., 2015, Águas de Lindóia. Anais [...]. Águas de Lindóia/SP: ABRAPEC, 2015.

MORAES, F. N. O "Não Lugar" do Ensino de Biotecnologia: Uma Perspectiva de Construção Discursiva. In: XII Encontro Nacional de Pesquisa em Educação em Ciências - ENPEC, 12., 2018, Natal. Anais [...]. Natal/RN: ABRAPEC, 2019.

NASCIMENTO, T. G.; ALVETTI, M. A. S. Temas científicos contemporâneos no Ensino de Biologia e Física. Ciência \& Ensino, v. 1, n. 1, dez. 2006.

ORLANDI, E. P. Análise de Discurso: princípios e procedimentos. Campinas: Pontes, 2003.

ORLANDI, E. P. Interpretação - autoria, leitura e efeitos do trabalho simbólico. Petrópolis: Vozes, 1996.

ORLANDI, E. P. As formas do silêncio. No movimento dos sentidos. Campinas: Ed. da Unicamp, 2007.

PÊCHEUX, M. O discurso: estrutura ou acontecimento. Tradução de Eni. P. Orlandi. 4 ed. Campinas: Pontes, 1990.

SARDINHA, R.; FONSECA, M.; GOLDBACH, T. O que dizem os trabalhos dos anais dos Encontros Nacionais de Pesquisa em Ensino de Ciências sobre o Ensino de Genética. In: VII Encontro Nacional de Pesquisa em Educação em Ciências - ENPEC, 7., 2009, Anais [...]. Florianópolis: ABRAPEC, 2010.

LOPES, E. S., GÜLLICH, R. I. C. Ensino de genética no Brasil: um panorama das concepções e estratégias didáticas. Práxis Pedagógica, 20(26), p. 95-116, 2020.

SILVA, L. N. S.; MEGLHIORATTI, F. A. Análise de livros didáticos de Biologia em periódicos de ensino: o que trazem as pesquisas? VIDYA, v. 40, n. 1, p. 259-278, jan./jun., 2020. 
Edição Especial: I SSAPEC - Simpósio Sul-Americano de Pesquisa em Ensino de Ciências

STEPHENS, P. R. S.; OLIVEIRA, M. B. S. C.; RIBEIRO, F. C. R.; CARNEIRO, L. A. D. Virologia. In: Amendoeira, M. Conceitos e métodos para a formação de profissionais em laboratórios de saúde. Rio de Janeiro: EPSJV, 2009.

TRAVESSAS, A. O.; GARNERO, A. D. V.; MARINHO, J. C. B. Recursos didáticos alternativos para o ensino de Genética e Evolução. Revista Eletrônica Ludus Scientiae, v. 4, n. 2, p. 261-282, 2020. 